\title{
Sexual Behavior and Sexually Transmitted Diseases in Street-Based Female Sex Workers in Rajshahi City, Bangladesh
}

\author{
Nazrul Islam Mondal ${ }^{1}$, Kamal Hossain ${ }^{1}$, Rafiqul Islam $^{1}$ and Abul Bashar Mian ${ }^{2}$ \\ ${ }^{1}$ Department of Population Science and Human Resource Development; ${ }^{2}$ Institute of Bangladesh Studies; Rajshahi, Bangladesh
}

\begin{abstract}
We analyzed the sexual behavior and sexually transmitted diseases (STDs) of street-based female sex workers (SFSWs) of Rajshahi city and examined their socio-demographic profiles. Among the SFSWs attending three dropin centers (DIC) named PIACT, PROVA, and Suraksha Madhumita in Rajshahi, 150 self-motivated and willing individuals were interviewed through a structured questionnaire to obtain obstetric histories and socio-demographic information. Among these SFSWs, $56.7 \%$ were infected with two or more pathogens of STDs, with gonorrhea, chlamydia, herpes, syphilis, and trichomoniasis observed in $23.3,27.3,24.0,17.3$, and 20.0\%, respectively. We found a strong association between the prevalence of STDs among SFSWs and their socio-demographic profiles. Illiterate and comparatively older SFSWs who spent very little money for health purposes, had larger numbers of children, and used condoms inconsistently were observed to be at higher risk of STDs. These results observed with bivariate analysis were also confirmed by logistic regression analysis.
\end{abstract}

Key-Words: Sexual behaviors, HIV/AIDS, STDs, SFSWs, Bangladesh.

Sexually transmitted diseases (STDs) can be painful, irritating, unbearable, and life threatening. More than 25 STDs have been identified, and they occur most commonly in sexually-active teenagers and young adults, especially those with multiple sex partners [1]. Most STDs cause relatively harmless diseases, producing few or no symptoms. However, some produce persistent and symptomatic or minimally symptomatic disease. Some people carry the disease for days or weeks, while others carry the disease for longer periods, even for life. During this time, an infected individual or carrier can spread the disease. In persistent infection, the pathogen evades detection by the immune system and remains fairly inactive, causing no overt disease. However, certain triggers can reactivate latent pathogens [2]. In some cases, reactivated disease is symptomatic; in others, it is overt; and in still others, severe and even fatal. Complications of STD infection include pelvic inflammatory disease (PID) and inflammation of the cervix in women, inflammation of the urethra and inflammation of the prostate in men, and fertility and reproductive system problems in both sexes. Possible consequences for an infant infected while in the womb or during birth include stillbirth, blindness, and permanent neurological damage. A person infected with an STD is more likely to become infected with human immunodeficiency virus (HIV), and a person infected with HIV and other STDs are more likely to transmit HIV. Consequently, STDs pose an enormous burden in many countries as a direct result of their effects on reproductive and child health and indirectly by facilitating sexual transmission of HIV infection [3]. Consequently, STDs have been identified as a predisposing factor in the transmission of

Received on 12 April 2008; revised 22 July 2008.

Address for correspondence: Dr. Nazrul Islam Mondal. Department of Population Science and Human Resource Development. University of Rajshahi. Rajshahi-6205, Bangladesh. Phone: +88-0721-751217, Mobile: +88-01716389187. E-mail: nazrul_ru@yahoo.com.

The Brazilian Journal of Infectious Diseases 2008;12(4):287-292. (C) 2008 by The Brazilian Journal of Infectious Diseases and Contexto Publishing. All rights reserved.
HIV, while acquired immune deficiency syndrome (AIDS) has become one of the five most important causes of death in the world [4].

Bangladesh formed the National AIDS Committee in 1985, giving top priority to education about how sexual behaviors can help control and prevent HIV/AIDS, though the first AIDS case was not detected until 1989 [5]. In Bangladesh, there are approximately 100,000 commercial sex workers (CSWs), who are distributed in urban, semi-urban, and rural areas, either organized in brothels, or working as independent sex workers [6]. Female CSWs play an important role in the heterosexual transmission of HIV. These sex workers have been considered to be the most important reservoir of STDs and a high-risk population for STDs and HIV [7]. Control of STDs among them would have a significant impact upon the spread of HIV [8]. Sexually transmitted diseases are a major public health problem in developing countries, including Bangladesh. The prevalence of reproductive tract infections (RTIs) and STDs among females in the general population and among street female sex workers (SFSWs) in Bangladesh is not well documented. In a cross-sectional study among slum dwellers in Dhaka city, the prevalence of gonorrhea and syphilis were observed to be $1.00 \%$ and $11.50 \%$ respectively [9]. A recent study revealed a prevalence of $28 \%$ for gonorrhea and/or chlamydia among the brothel based sex workers, while $57.1 \%$ of SFSWs were positive for syphilis, though none were HIV positive [10]. The prevalence of gonorrhea among CSWs and the antimicrobial susceptibility of the isolates were subsequently studied; $42 \%$ of the CSWs were found to be culture positive for gonorrhea [11, 12]. A prospective study was conducted to determine the prevalence of herpes simplex virus type-2 (HSV-2) in Bangladeshi CSWs; it was concluded that this group is particularly at risk of acquiring and transmitting HSV-2 and other STDs [13]. A prevalence study was conducted on STDs at the Tangail brothel in Bangladesh; it was concluded that women are at a greater risk for sexually transmitted infections (STIs) [14]. Truck drivers are a recognized high-risk group for STDs and HIV. Bangladeshi 
women living adjacent to truck stops are at greater risk for STDs [15]. An etiological study of STIs was conducted by Rahman et al. [16] among female sex workers in Dhaka, Bangladesh; 84\% were positive for STI pathogens. Rajshahi City is very near the Indian border; hence Indian truck drivers often stay there and rickshaw drivers also go there from different districts; many of them have sex with SFSWs. Understanding the sexual habits and the symptoms of STDs in SFSWs is an important step in the endeavor towards preventing STDs. We examined the prevalence and the risk factors involved in STDs among SFSWs in Rajshahi City, Bangladesh. Possibly our findings will help policy makers, government agencies, and health managers, to formulate appropriate strategies to improve STDs/STIs awareness and prevention activities.

\section{Material and Methods}

From November to December 2006, a cross sectional study on STDs was conducted among SFSWs attending the DIC in Rajshahi city, Bangladesh. The SFSWs attending the rehabilitation centers were enrolled in the study irrespective of their STD symptoms. All eligible SFSWs were requested to participate in the study after being given a brief description of the purpose and procedures of the study. To investigate socio-demographic information on SFSWs, 150 SFSWs were selected as the study population, using a purposive sampling design. A structured questionnaire was developed to explore the basic symptoms of STDs, after a long discussion with an expert in this area. A personal interview approach was followed for the purpose of data collection. The SFSWs were directly interviewed and the information was collected with the questionnaire. The data were analyzed by using the Statistical Package for Social Sciences (SPSS), version 10.0. A contingency analysis was used to test for association between the different phenomena on the basis of classification of variables or attributes by applying the Chi-square $\left(\chi^{2}\right)$ test, in which $\chi^{2}=\sum \frac{O_{i j}{ }^{2}}{E_{i j}}-N$, follows a $\chi^{2}$ distribution with (r-1)(c$1)$ degrees of freedom. A logistic regression analysis was performed in order to observe the effects of the independent variables $(\mathrm{X})$ on the dependent variable $(\mathrm{Y})$.

The logistic function can be written as:

$E(Y \mid Z=z)=\frac{e^{z}}{1+e^{z}}$ where, $z=\beta_{0}+\beta_{1} X_{1}+\beta_{2} X_{2}+\beta_{3} X_{3}+\beta_{4} X_{4}+\beta_{5} X_{5}$ are regression parameters, and $\beta_{0}, \beta_{1}, \beta_{2}, \beta_{3}, \beta_{4}$, and $\beta_{5}$ are unknown constants to be determined from the data.

For the predicted variable

$Y_{\mathrm{i}}=\mathrm{STDs}=\left\{\begin{array}{l}1, \text { if } \text { STDs occurred } \\ 0, \text { otherwise }\end{array}\right.$

and for the explanatory variables

$\mathrm{X}_{1}=$ age $=\left\{\begin{array}{l}1, \text { if age }>30 \text { years } \\ 0, \text { otherwise }\end{array}\right.$

$\mathrm{X}_{2}=$ no. of children $=\left\{\begin{array}{l}1, \text { if the no. of children }>3 \\ 0, \text { otherwise }\end{array}\right.$
$\mathrm{X}_{3}=$ education $=\left\{\begin{array}{l}1, \text { if literate }, \\ 0, \text { otherwise } ;\end{array}\right.$

$\mathrm{X}_{4}=$ expenditure on health $=\left\{\begin{array}{l}1, \text { if yes, } \\ 0, \text { otherwise } ;\end{array}\right.$

$\mathrm{X}_{5}=$ condom use $=\left\{\begin{array}{l}1, \text { if yes, } \\ 0, \text { otherwise } .\end{array}\right.$

\section{Results}

Prevalence of STDs

It is not uncommon in some rural areas in Bangladesh, particularly among young people in the lower economic strata, for husbands to abandon their wives and children and not take care of them. Most of the sex workers in our study were victims of such a situation. These unfortunate women, additionally handicapped by illiteracy, are compelled to support themselves and their children through sex work. Table 1 shows their socioeconomic characteristics. TheSFSWs in Rajshahi City were engaged in risky sexual behaviors. More than half (60\%) of the study population was less than 30 years of age, $100 \%$ had been married but $90.7 \%$ had separated, $7 \%$ had one to two children, and $58.7 \%$ did not have any formal education. Numerical information on the prevalence of STDs among the SFSWs is presented in Table 2 . We found that $56.67 \%$ of the SFSWs had mixed infections with two or more pathogens (STDs), and a small portion had combined infections with all five pathogens. Among 150 SFSWs, 23.3\% had gonorrhea, 27.3\% had Chlamydia, 24\% had herpes, $17.3 \%$ had syphilis, $20 \%$ had Trichomoniasis, and $56.7 \%$ were infected by at least two pathogens (STDs). The prevalence of STDs among them was very high, as expected, because there is no effective intervention strategy implemented for this vulnerable group. These results are similar to what was found in previous studies in Bangladesh and some African countries [11, 12]. High rates of STDs were also found in similar groups in African countries, with gonorrhea rates of up to $51 \%$ in Rwanda, of 30 to $55 \%$ in Kenya, and of up to $31 \%$ in the Ivory Coast $[7,17]$. The prevalences of chlamydia and trichomoniasis were $27.3 \%$ and $20 \%$, respectively, also similar to what was found in a study made in Africa [18]. The prevalence rate of syphilis was $17.33 \%$, which is lower than the $57 \%$ prevalence found in a brothel-based study in Bangladesh [10]. The high prevalence of STDs are due to low awareness, limited access to sexual health information and unavailability of adequate health care services, poor literacy, poverty, and unemployment [19]. Thus, the SFSWs are considered the main high-risk group for STDs in this study area.

\section{Socio-Demographic Informations}

Cross-classification analysis ( $\chi^{2}$ test) has been used to examine possible associations between socio-demographic factors and other predicting factors for STDs among SFSWs. In our study, STDs were common; their frequency varied with various socio-demographic characteristics. Table 3 shows the association of STDs, gonorrhea, chlamydia tracomatis, herpes, 
Table 1. Socio-demographic characteristics of street-based female sex workers in Rajshahi City, Bangladesh.

\begin{tabular}{llcc}
\hline Characteristics & Covariates & Total & Percentage (\%) \\
\hline Age group (years) & $<20$ & 28 & $18.7 \%$ \\
& $20-30$ & 62 & $41.3 \%$ \\
\multirow{4}{*}{ Marital status } & $30+$ & 60 & $40.0 \%$ \\
& Unmarried & 0 & $0 \%$ \\
& Married (with husband) & 2 & $1.3 \%$ \\
& Divorced & 6 & $4.0 \%$ \\
& Separated & 136 & $90.7 \%$ \\
Educational status & Widowed & 6 & $4.0 \%$ \\
& Illiterate & 88 & $58.7 \%$ \\
& Literate & 62 & $41.3 \%$ \\
& 0 & 6 & $4.0 \%$ \\
& $1-2$ & 76 & $50.7 \%$ \\
& $3-4$ & 55 & $36.7 \%$ \\
& $4+$ & 13 & $8.7 \%$ \\
\hline
\end{tabular}

Table 2. The prevalence of symptoms of sexually-transmitted diseases (STDs) of street-based female sex workers in Rajshahi City, Bangladesh.

\begin{tabular}{llcc}
\hline Characteristics & Covariates & Total & Percentage (\%) \\
\hline Etiological diagnosis & STDs & 80 & $53.3 \%$ \\
& Gonorrhea & 38 & $25.3 \%$ \\
& Chlamydia Trachomatis & 41 & $27.3 \%$ \\
& Herpes & 37 & $24.7 \%$ \\
& Syphilis & 26 & $17.3 \%$ \\
& Trichomoniasis & 30 & $20.0 \%$ \\
\hline
\end{tabular}

syphilis, and trichomoniasis with the respondents' age, education, spending on health, number of children, and condom use.

Older age-group SFSWs had more symptoms of STDs; with increasing age, gonorrhea, chlamydia, herpes, syphilis and trichomoniasis also increased. Respondents' age and STD frequency was highly associated, except for trichomoniasis $(p=0.232)$. T There was a highly significant association between age and STDs $(\mathrm{p}=0.000)$, gonorrhea $(\mathrm{p}=0.006)$, chlamydia $(\mathrm{p}=0.000)$, herpes $(\mathrm{p}=0.009)$, and syphilis $(\mathrm{p}=0.000)\left(\chi^{2}\right.$ test $)$.

Health condition of SFSWs is a major factor for controlling infections or diseases; these women are frequently infected because of sexual contacts. Obviously, unhealthy SFSWs have less resistance to these diseases than healthy SFSWs. The SFSWs who had spent money on their heath lead a healthy life, had few symptoms of STDs. The SFSWs who spent money for health purposes infrequently had symptoms of syphilis (2.66\%). On the other hand, among those who did not invest in their health, syphilis was considerably more common (14.66\%). There was a highly significant association between expenditure on health and all components of STDs, such as educational status of respondents $(\mathrm{p}=0.000)$.

Education is the most consistent and important determinant for prevention of STDs among all classes of people. Literate SFSWs have a lower incidence of STDs than illiterate SFSWs. Less than $2 \%$ of literate SFSWs have gonorrhea compared to $34 \%$ of illiterate SFSWs; similar patterns have been found for other components of STDs. There is a highly significant (negative) relationship ( $\chi^{2}$ test, $\mathrm{p}=0.000$ ) between educational status of respondents and all components of STDs.

Children play an important role in frequency of STDs among SFSWs. The SFSWs who have never had children less frequently have STDs (1.33\%) than those who have one to two children (24.66\%) three to four children (23.33\%). On the other hand, those who have $>4$ children) less frequently $(4.00 \%)$ have STDs. Only herpes $(p=0.005)$ and syphilis $(\mathrm{p}=0.002)$ varied significantly among these groups.

Condom users are not only safe from STDs but also safe from dangerous diseases such as HIV/AIDS. Unfortunately, because of the competitive market and the fear of losing clients, most sex workers in our study agree to unprotected sex when they are coerced or offered extra money. The respondents who used condoms during sexual intercourse had fewer symptoms of STDs than those who did not use condoms. Among SFSWs who normally use condoms with $6.66 \%$ had syphilis, compared to $10.66 \%$ who did not use condoms when they had intercourse with clients. The difference was significant for most STDs ( $\mathrm{p}=0.000)$, but (non-significant) inverse results were found for trichomoniasis $(\mathrm{p}=0.160)$. 
Table 3. Association of the sexually transmitted diseases, gonorrhea, chlamydia, herpes, syphilis, and trichomoniasis with socio-demographic characteristics.

\begin{tabular}{|c|c|c|c|c|c|c|c|c|c|c|c|c|}
\hline \multirow{2}{*}{$\begin{array}{l}\text { Etiological } \\
\text { diagnosis } \\
\text { Characteristics }\end{array}$} & \multicolumn{2}{|c|}{ STDs (\%) } & \multicolumn{2}{|c|}{ Gonorrhea (\%) } & \multicolumn{2}{|c|}{ Chlamydia (\%) } & \multicolumn{2}{|c|}{ Herpes (\%) } & \multicolumn{2}{|c|}{ Syphilis (\%) } & \multicolumn{2}{|c|}{$\begin{array}{l}\text { Trichomoni- } \\
\text { asis (\%) }\end{array}$} \\
\hline & $\mathbf{P}$ & $\mathbf{N}$ & $\mathbf{P}$ & $\mathbf{N}$ & $\mathbf{P}$ & $\mathbf{N}$ & $\mathbf{P}$ & $\mathbf{N}$ & $\mathbf{P}$ & $\mathbf{N}$ & $\mathbf{P}$ & $\mathbf{N}$ \\
\hline \multicolumn{13}{|l|}{ Age group } \\
\hline$<20$ & $\begin{array}{l}6 \\
(4.00)\end{array}$ & $\begin{array}{l}22 \\
(14.70)\end{array}$ & $\begin{array}{l}5 \\
(3.30)\end{array}$ & $\begin{array}{l}22 \\
(14.7\end{array}$ & $\begin{array}{l}3 \\
(2.0)\end{array}$ & $\begin{array}{l}25 \\
(33.0)\end{array}$ & 4 & $\begin{array}{l}24 \\
(33.0\end{array}$ & $\begin{array}{l}0 \\
(0.00)\end{array}$ & $\begin{array}{l}28 \\
(33.00)\end{array}$ & $\begin{array}{l}3 \\
(2.00)\end{array}$ & $\begin{array}{l}25 \\
(33.00)\end{array}$ \\
\hline $20-30$ & $\begin{array}{l}27 \\
(18.00)\end{array}$ & $\begin{array}{l}35 \\
(23.30)\end{array}$ & $\begin{array}{l}10 \\
(6.70)\end{array}$ & $\begin{array}{l}52 \\
(34.70)\end{array}$ & $\begin{array}{l}11 \\
(7.30)\end{array}$ & $\begin{array}{l}51 \\
(34.0)\end{array}$ & $\begin{array}{l}11 \\
(7.30)\end{array}$ & $\begin{array}{l}51 \\
(34.00)\end{array}$ & $\begin{array}{l}5 \\
\text { (3.33) }\end{array}$ & $\begin{array}{l}57 \\
(38.00)\end{array}$ & $\begin{array}{l}16 \\
(10.70)\end{array}$ & $\begin{array}{l}46 \\
(30.70)\end{array}$ \\
\hline $30+$ & $\begin{array}{l}47 \\
(31.30)\end{array}$ & $\begin{array}{l}13 \\
(8.70)\end{array}$ & $\begin{array}{l}23 \\
(15.30)\end{array}$ & $\begin{array}{l}38 \\
(25.30)\end{array}$ & $\begin{array}{l}27 \\
(18.00)\end{array}$ & $\begin{array}{l}33 \\
(22.00)\end{array}$ & $\begin{array}{l}22 \\
(14.70)\end{array}$ & $\begin{array}{l}38 \\
(25.30)\end{array}$ & $\begin{array}{l}21 \\
(14.00)\end{array}$ & $\begin{array}{l}39 \\
(26.00)\end{array}$ & $\begin{array}{l}11 \\
(7.33)\end{array}$ & $\begin{array}{l}49 \\
(32.70)\end{array}$ \\
\hline $\begin{array}{l}\chi^{2} \text { value } \\
\text { Df, asymp. sig. }\end{array}$ & $\begin{array}{l}28.904 \\
d f=2, p\end{array}$ & 0.000 & $\begin{array}{l}10.254 \\
d f=2, p\end{array}$ & 0.006 & \multicolumn{2}{|c|}{$\mathrm{df}=2, \mathrm{p}=0.000$} & \multicolumn{2}{|c|}{$\mathrm{df}=2, \mathrm{p}=0.009$} & \multicolumn{2}{|c|}{$\mathrm{df}=2, \mathrm{p}=0.000$} & \multicolumn{2}{|c|}{$\mathrm{df}=2, \mathrm{p}=0.232$} \\
\hline
\end{tabular}

Expenditure on health

$\begin{array}{cllllllllllll}\text { No } & 69 & 18 & 28 & 59 & 33 & 54 & 31 & 56 & 22 & 65 & 26 & 61 \\ & (46.00) & (12.00) & (18.66) & (39.30) & (22.00) & (36.00) & (20.70) & (37.30) & (14.66) & (43.66) & (17.33) & (40.66) \\ \text { Yes } & 11 & 52 & 7 & 56 & 8 & 55 & 5 & 58 & 4 & 59 & 4 & 59 \\ & (7.33) & (34.70) & (4.66) & (37.30) & (5.33) & (36.66) & (3.33) & (38.7) & (2.66) & (39.33) & (2.66) & (39.33) \\ \chi^{2} \text { value } & 56.162 & & 9.070 & & 11.713 & & 15.366 & & 9.146 & & 12.651 \\ \text { Df, asymp. sig. } & \mathrm{df}=1, \mathrm{p}=0.000 & \mathrm{df}=1, \mathrm{p}=0.003 & \mathrm{df}=1, \mathrm{p}=0.001 & \mathrm{df}=1, \mathrm{p}=0.000 & \mathrm{df}=1, \mathrm{p}=0.000 & \mathrm{df}=1, \mathrm{p}=0.000\end{array}$

(2-sided)

Educational status

$\begin{array}{rllllllllllll}\text { Illiterate } & 80 & 15 & 34 & 61 & 40 & 55 & 36 & 59 & 26 & 59 & 29 & 59 \\ & (53.33) & (10.00) & (22.66) & (40.66) & (26.66) & (36.66) & (24.00) & (39.30) & (17.33) & (46.00) & (19.33) & (39.33) \\ \text { Literate } & 0 & 55 & 1 & 54 & 2 & 53 & 0 & 55 & 0 & 55 & 1 & 61 \\ & (0.00) & (36.66) & (0.66) & (36.00) & (1.33) & (35.33) & (0.00) & (36.70) & (0.00) & (36.66) & (0.66) & (40.66) \\ \chi^{2} \text { value } & 99.248 & & 22.472 & & 8.464 & & 27.424 & & 18.209 & & 17.943 \\ \text { Df, asymp. sig. } & \mathrm{df}=1, \mathrm{p}=0.000 & \mathrm{df}=1, \mathrm{p}=0.000 & \mathrm{df}=1, \mathrm{p}=0.000 & \mathrm{df}=1, \mathrm{p}=0.000 & \mathrm{df}=1, \mathrm{p}=0.000 & \mathrm{df}=1, \mathrm{p}=0.000 \\ \text { (2-sided) } & & & & & & & & & & & & \end{array}$

Number of children

$\begin{array}{cllllllllllll}0 & 2 & 4 & 1 & 5 & 1 & 5 & 0 & 6 & 1 & 5 & 2 & 4 \\ & (1.33) & (2.66) & (0.66) & (3.33) & (0.66) & (3.33) & (0.00) & (4.0) & (0.66) & (3.33) & (1.33) & (2.66) \\ 1-2 & 37 & 39 & 17 & 59 & 16 & 60 & 12 & 64 & 5 & 71 & 17 & 59 \\ & (24.7) & (26.00) & (11.33) & (39.33) & (10.66) & (40.00) & (8.00) & (42.7) & (3.33) & (47.33) & (11.33) & (39.33) \\ 3-4 & 35 & 20 & 16 & 39 & 20 & 35 & 22 & 33 & 18 & 37 & 10 & 45 \\ & (23.30) & (13.33) & (10.66) & (26.00) & (13.33) & (23.33) & (14.66) & (22.00) & (12.00) & (24.66) & (6.66) & 30.00) \\ 5+ & 6 & 7 & 1 & 12 & 4 & 9 & 2 & 11 & 2 & 11 & 1 & 12 \\ & (4.00) & (4.66) & (0.66) & (8.00) & (2.66) & (6.00) & (1.33) & (7.33) & (1.33) & (7.33) & (0.66) & (8.00) \\ \chi^{2} \text { value } & 4.239 & & 2.986 & & 4.188 & & 12.952 & & 15.267 & & 2.278 \\ \text { Df, asymp. sig. } & \mathrm{df}=3, \mathrm{p}=0.237 & \mathrm{df}=3, \mathrm{p}=0.394 & \mathrm{df}=3, \mathrm{p}=0.242 & \mathrm{df}=3, \mathrm{p}=0.005 & \mathrm{df}=3, \mathrm{p}=0.002 & \mathrm{df}=3, \mathrm{p}=0.517\end{array}$

(2-sided)

Consom use

\begin{tabular}{cllllllllllll} 
No & 47 & 16 & 19 & 44 & 23 & 40 & 24 & 39 & 16 & 47 & 16 & 47 \\
& $(31.30)$ & $(10.66)$ & $(12.66)$ & $(29.33)$ & $(15.33)$ & $(26.66)$ & $(16.00)$ & $(26.00)$ & $(10.66)$ & $(31.33)$ & $(10.66)$ & $(31.33)$ \\
Yes & 33 & 54 & 16 & 71 & 18 & 69 & 12 & 75 & 10 & 77 & 14 & 73 \\
& $(22.00)$ & $(36.00)$ & $(10.66)$ & $(47.33)$ & $(12.00)$ & $(46.00)$ & $(8.00)$ & $(50.00)$ & $(6.66)$ & $(51.33)$ & $(9.33)$ & $(48.66)$ \\
$\chi^{2}$ value & 19.744 & & 2.829 & & 4.603 & & 11.831 & 4.929 & & 1.977 & \\
$\begin{array}{l}\text { Df, asymp. sig. } \\
\text { (2-sided) }\end{array}$ & $\mathrm{df}=1, \mathrm{p}=0.000$ & $\mathrm{df}=1, \mathrm{p}=0.093$ & $\mathrm{df}=1, \mathrm{p}=0.032$ & $\mathrm{df}=1, \mathrm{p}=0.001$ & $\mathrm{df}=1, \mathrm{p}=0.026$ & $\mathrm{df}=1, \mathrm{p}=0.160$ \\
\hline
\end{tabular}

Numbers in parentheses indicate the percentages of the total. $\mathrm{P}=$ positive; $\mathrm{N}=$ negative; $\mathrm{Df}=$ degrees of freedom. 
Table 4. Logistic regression for the relative risk of sexually transmitted diseases among street-based female sex workers.

\begin{tabular}{|c|c|c|c|c|}
\hline Characteristics & Coefficient ( $\beta$ ) & SE of estimates $(\beta)$ & Significance (p) & Relative risk (odds ratio) \\
\hline \multicolumn{5}{|l|}{ Age } \\
\hline$<30$ years $(\mathrm{RC})$ & - & - & - & 1.000 \\
\hline$>30$ years & 0.888 & 0.722 & 0.220 & 2.422 \\
\hline \multicolumn{5}{|l|}{ Number of children } \\
\hline$<3(\mathrm{RC})$ & - & - & - & 1.000 \\
\hline$>3$ & 0.019 & 0.584 & 0.975 & 1.019 \\
\hline \multicolumn{5}{|l|}{ Educational status } \\
\hline Illiterate (RC) & - & - & - & 1.000 \\
\hline Literate & 1.924 & 0.540 & $0.000 *$ & 0.146 \\
\hline \multicolumn{5}{|l|}{ Expenditure on health } \\
\hline No(RC) & - & - & - & 1.000 \\
\hline Yes & 2.649 & 0.497 & $0.000 *$ & 0.71 \\
\hline \multicolumn{5}{|l|}{ Use of condom } \\
\hline No(RC) & - & - & - & 1.000 \\
\hline Yes & 1.390 & 0.502 & $0.006^{*}$ & 0.249 \\
\hline Constant & 0.330 & 0.450 & 0.463 & \\
\hline -2 log likelihood model & 115.115 & & & \\
\hline Chi-square & 92.162 & & & \\
\hline Degrees of freedom & 5 & & & \\
\hline
\end{tabular}

Determinants of Influencing Factors

The results obtained from logistic regression analysis are presented in Table 4, using STDs as the predictor variable and socio-demographic variables as explanatory variables. The results are shown in terms of odds ratios obtained by calculating the exponential function of estimated regression coefficients. In the bivariate analysis, relationships between the types of STDs (gonorrhea, chlamydia trachomatis, herpes, syphilis and trichomoniasis) and socio-demographic factors were studied. This analysis was designed to identify the indicators that have an influence on the prevalence of STDs.

The estimated regression coefficient for respondents whose age was 30 years and above was 0.888 and the odds ratio was 2.422, which shows that age has a positive effect on the prevalence of STDs among the SFSWs. The risk was 2.422 times higher for those belonging to the age group 30 or older in comparison to those younger than 30 years. Similarly, larger number of children were associated with more frequent STDs.

Education is an important determinant of STDs for SFSWs. The regression coefficient and odds ratio for literacy of SFSWs were -1.924 and 0.146 , respectively. This implies that literacy of SFSWs had a highly significant negative impact on the prevalence of STDs. This suggests that if SFSWs are provided minimum fundamental education, STDs will decrease, as will the risk of STIs and HIV/AIDS. Furthermore, the SFSWs who money on their health and who consistently used of condoms had a significantly lower risk of developing STDs (29 and $75.1 \%$, respectively).

Treatment and Prevention

Viral STDs cannot be cured fully, but symptoms can be managed with medication. The following behaviors and conditions can increase the risk of STDs: i) engaging in sexual activity when either partner has unhealed lesions, ii) enema or rectal douching before rectal intercourse, iii) rectal or vaginal irritation or infection, iv) sexual activity that may damage the mucosal lining of the vagina or rectum, v) tampon use, and vi) vaginal dryness. Bacterial STDs, such as gonorrhea and chlamydia, can be cured with antibiotics. Fungal and parasitic diseases can be cured with anti-fungal and anti-helminth agents, respectively. Early diagnosis and treatment increase the chances for cure.

The only sure way to avoid becoming infected with an STD is monogamy with an uninfected partner. It is important for partners to discuss their sexual and STD histories before having sex. Prevention is possible only if sexually active individuals understand STDs and how they spread. The risk for transmission is dramatically reduced with the use of condoms. Well-trained and motivated human resources, such as religious leaders, teachers, and community leaders are important for achieving success in HIV/AIDS/STD interventions at all levels. Unfortunately, in Bangladesh the performance of health workers, teachers, and religious places in disseminating AIDS information is very poor, although they are widely available all over the country. To improve this situation, HIV/AIDS campaigns will have to pay much more attention to educate religious and traditional leaders. Health workers should be trained and the education sector should address STD/HIV/AIDS prevention strategies. Moreover, other strategies, such as face-to-face communication, sexual education and continuous monitoring could be effective in Bangladesh.

\section{Discussion}

The high prevalence of some infectious diseases indicates the need to implement prevention interventions for these SFSWs, and perhaps more importantly, involve their male clients. 
Low levels of knowledge and little expenditure on health, more children, older age, high-risk sexual behaviors, and lack of condom use during sexual activity, together with the high prevalence of STDs among SFSWs, suggest that they are at greater risk of HIV infection. Unfortunately, little information is available on STIs in the Bangladesh population and especially concerning this vulnerable group. Yet it is only in recent years that these diseases have been accorded any priority by ministers of health or by international agencies. There have been no effective intervention strategies implemented among SFSWs who are an important reservoir and high-risk population for STDs and HIV. The data on STDs and related complications are limited, which means that the burden of these diseases is substantially underestimated; STDs are often asymptomatic and are technically difficult and often expensive to diagnose. Therefore, gathering information on STDs and sexual practices prevailing among SFSWs, and adopting protective measures against infection, are of paramount importance in developing intervention programs. Moreover, qualitative research is needed to provide insights into their sexual behavior and the contexts in which high-risk behaviors occur.

\section{Recommendations}

The SFSWs in Rajshahi City are deprived of all health assistance. Moreover, they are illiterate and ignorant about their physical fitness, nutritional status, and about STDs. As a result, they are at high risk of spreading various STIs/STDs, and consequently HIV infection. To improve the overall health situation and alleviate most of the risks, the following steps should be adopted:

a. The existing level of awareness and major sources of knowledge about STIs/STDs, health status, and correct information about the transmission as well as prevention of these diseases should be improved, and initiatives should be made so that all SFSWs have access to this information.

b. Along with governmental and nongovernmental organizations, social and religious leaders should take measures to increase the awareness of SFSWs about family laws. Large numbers of women are unaware of marital rights and ultimately choose this profession, finding no other means of sustenance for themselves and their children.

c. Priority should be given for the treatment of STIs/STDs, and access to hospitals and clinics should be facilitated. Also, the number of clients per night should be maintained within tolerable limits.

d. Care and support programs as well as regular medical check-up and voluntary counseling and testing should be strengthened by both government and nongovernment programs. We also need to take concrete steps to change the mentality of this ostracized group.

e. Special training for SFSWs is needed so that they learn to use female condoms; this, along with sex education, knowledge about healthy sexual behaviors, and instruction about correct use of male condoms would substantially reduce the risk of health complications and greatly reduce the spread of STDs.

\section{Acknowledgements}

Part of this research was conducted under a project financed by UNFPA; the authors are thankful for this support. We are also grateful to the SFSWs in Rajshahi City, Bangladesh for cooperating and providing information. Last but not least, our sincere gratitude to the comments from anonymous reviewers for improving this article.

\section{References}

1. Eng T.R., Butler W.T. The Hidden Epidemic - Confronting Sexually Transmitted Disease. Institute of Medicine. Washington, DC: National Academy Press; 1997.

2. Centers for Disease Control and Prevention (CDCP). Summary of notifiable disease, US 1998. MMWR Morb Mortal Wkly Rep 1999;47(53):1-93.

3. Vuylsteke B., Laga M., Alary M., et al. Clinical algorithms for the screening of women for gonococci and chlamydia infection: evaluation of pregnant women and prostitutes in Zaire. Clin Infect Dis 1993;17:82-8.

4. Piot P., Bartos M., Ghys P.D., et al. The global impact of HIV/ AIDS. Nature 2001;410:968-73.

5. Director General of Health Services (DGHS). Strategic Plan of National AIDS Program of Bangladesh 1997-2002. Bangladesh AIDS Prevention and Control Program. Director General of Health Services Ministry of Health and Family Welfare, Government of the People's Republic of Bangladesh, Dhaka; 2000.

6. Choudhury M.R., Islam N., Rasul G. Meeting the challenges of HIV/AIDS in Bangladesh. Bangladesh AIDS prevention and control program, Dhaka, Bangladesh, 1997:19.

7. D'Costa L.J., Plummer F.A., Bowmer I., et al. Prostitutes are a Major Reservoir of Sexually Transmitted Diseases in Nairobi, Kenya. Sex Transm Dis 1985;12:64-7.

8. Bhave G., Lindan C.P., Hudes E.S., et al. Impact of an intervention on HIV/AIDS, sexually transmitted diseases, and condom use among sex workers in Bombay, India. AIDS 1995;(Suppl 1):S21-30.

9. Sabin K., Rahman M., Hawkes S, et al. Programs Abstr. Sixth Annual Sci Conf 1997; [abstr. 13].

10. Sarker S., Islam N., Durandin F., and et al. Low HIV and high STD among commercial sex workers in a brothel in Bangladesh: scope for prevention of larger epidemic. Int J STD AIDS 1998;9:45-57.

11. Bhuiyan B.U., Rahman M., Miah R.A., et al. High prevalence of ciprofloxacin resistant Neisseria gonorrhea among the commercial sex workers in Bangladesh. J Antimicrob Chemother 1998;48:675-6.

12. Bhuiyan B.U., Rahman M., Miah M.R.A., et al. Antimicrobial susceptibilities and plasmid contents of Neisseria gonorrhea isolates from commercial sex workers in Dhaka, Bangladesh: emergence of high-level resistance to ciprofloxacin. J Clin Microbiol 1999;37:1130-6.

13. Qutub M., Akter J. Epidemiology of genital herpes (HSV-2) among brothel based commercial sex workers in Bangladesh. European Journal of Epidemiology 2003;18:903-5.

14. Mondal M.N.I., Khan M.A.R., Islam M.R., Mamun A.A. Commercial sex workers in brothels are hallmark of HIV epidemic in Bangladesh. Pakistan Journal of Social Sciences 2005;3(9):1152-8.

15. Gibney L., Macaluso M., Kirk K., et al. Prevalence of infectious diseases in Bangladeshi living adjacent to a truck stand: HIV/STD/hepatitis/ genital tract infections. Sex Transm Inf 2001;77:344-50.

16. Rahman M., Alam A., Nessa K., et al. Etiology of sexually transmitted infections among street-based female sex workers in Dhaka, Bangladesh. Journal of Clinical Microbiology 2000,38:1244-6.

17. Meheus A., De Clercq A., Prat R. Prevalence of gonorrhea in prostitutes in a central African town. Br J Vener Dis 1974;50:50-2.

18. Ndoye I., Mboup S., De Schryver A., et al. Diagnosis of sexually transmitted infections in female prostitutes in Dakar, Senegal. Sex Transm Dis 1998;(Suppl 1):112-7.

19. Khan M.A. Knowledge on AIDS among the female adolescents in Bangladesh: evidence from the Bangladesh demographic and health survey data. Journal of Health and Population Nutrition 2002;20:130-7. 